\title{
Cooking Process: A New Source of Unintentionally Produced Dioxins?
}

\author{
Jiajia Wu, Shujun Dong, Guorui Liu, Bing Zhang, and Minghui Zheng* \\ State Key Laboratory of Environmental Chemistry and Ecotoxicology, Research Center for Eco-Environmental Sciences, \\ Chinese Academy of Sciences, Beijing 100085, China
}

\begin{abstract}
To improve understanding of human background exposure to dioxins, the influence of cooking on dioxin concentrations in food has received much attention. Studies have focused on changes in the distribution of dioxins that originate from raw foods. However, the possibility of dioxin formation during cooking has been neglected. In this study, cooking experiments were designed to investigate the generation of dioxins during cooking at high temperature and with flavorings containing organic chlorine. Solid, liquid, and gas phase samples were collected during cooking. The results indicate that dioxins can be generated during some cooking processes, such as burning, or when cooking with reactive organic chlorides, and the dioxins are more likely to be present in the smoke (gas phase) than the edible portion (solid and liquid phases). Thus, more attention should be given to cooking of raw foods and organic chlorine-containing flavorings at high temperature. Maintaining good ventilation during cooking is also necessary to reduce human exposure risk to dioxins.
\end{abstract}

KEYWORDS: cooking process, dioxins, food, organic chlorine-containing flavoring

\section{INTRODUCTION}

Polychlorinated dibenzo-p-dioxins and dibenzofurans (PCDD/Fs) are highly toxic and persistent compounds that are the unintentional products of anthropogenic activities, such as metal production and waste incineration. Formation of PCDD/Fs generally involves combustion of certain organic materials in the presence of chlorine and oxygen. ${ }^{1,2}$ With their sources widely distributed, PCDD/Fs are ubiquitous environmental pollutants and can accumulate in organisms through the food chain. It is estimated that $>90 \%$ of human exposure to $\mathrm{PCDD} / \mathrm{Fs}$ is through dietary intake, especially the consumption of animal products. ${ }^{3-5}$ To improve understanding of this exposure, the influence of the cooking on the concentrations of PCDD/Fs in food has received much attention.

Published data have focused on the cooking-induced changes in the distribution of $\mathrm{PCDD} / \mathrm{Fs}$ that originate from the raw foods; these studies have been limited to the edible portion (solid and liquid phases), whereas the smoke (gas phase) produced during cooking has not been considered. ${ }^{6-10}$ Animal products and leafy vegetables are cooked with different ordinary cooking processes, such as boiling, grilling, and roasting. It is reported that some cooking processes, such as grilling, could reduce the amount of PCDD/Fs in cooked products because these methods decrease the fat portion in the food. ${ }^{9,11}$ However, there is no strong evidence on the production of PCDD/Fs during cooking.

In this study, a series of cooking experiments were conducted to investigate the generation of PCDD/Fs during cooking at high temperature and with organic chlorine-containing flavorings. Beef and soybean oil were selected as representative of foods from animal origin and cooking oil, respectively. Using soybean oil as a heat transfer medium, a high temperature can be achieved during cooking, which increases the potential for chemical changes. Sucralose and 1,3-dichloro-2-propanol (1,3-DCP) were included as organic chloride sources to examine the factors affecting PCDD/F formation. In common use, sucralose is present widely in foods and beverages as a non-nutritive sweetener, whereas 1,3 -DCP is found as a contaminant in soy sauce and a range of other food ingredients. ${ }^{12}$ The quantities of PCDD/Fs in the solid, liquid, and gas phases before and after cooking were monitored and compared. These relative comparisons were used to study the transfer and formation of dioxins during cooking in this research.

\section{MATERIALS AND METHODS}

Chemicals and Materials. All organic solvents were of pesticide residue grade and obtained from J. T. Baker (Phillipsburg, NJ). Sucralose (purity $>98 \%$ ) was bought from Sigma-Aldrich, Inc. (St. Louis, MO), and 1,3-DCP (purity > 98\%) from Alfa Aesar (Ward Hill, MA). ${ }^{13} \mathrm{C}_{12^{-}}$ Labeled standards (EPA-1613LCS, ISS; EN-1948 SS, ES) specified in U. S. EPA Method $1613^{13}$ and European Method EN $1948^{14}$ were all purchased from Wellington Laboratories (Ontario, Canada). Beef and soybean oil were obtained from local supermarkets in April 2010. After collection, the beef samples were filleted and minced using a commercial meat mincer and then stored in the dark at $<-10{ }^{\circ} \mathrm{C}$ until use.

Cooking Process and Sample Collection. A purpose-built stainless steel apparatus was used to collect the gas and solid/liquid phases during cooking experiments. The schematic diagram of this apparatus is illustrated in Figure 1. During cooking, the gas phase was trapped using XAD-2 resin. Before sampling, ${ }^{13} \mathrm{C}_{12}$-labeled standards EN-1948 SS (1,2,3,7,8-PeCDF, 1,2,3,7,8,9-HxCDF, 1,2,3,4,7,8,9-HpCDF) were added to the $\mathrm{XAD}-2$ resin to monitor the sampling process. A stainless steel plate (diameter $=32 \mathrm{~cm}$ ) was placed between the bowl and the stove to stop fat splashing directly onto the stove during cooking.

Beef, soybean oil, sucralose, and 1,3-DCP were added under the different conditions given in Table 1 to verify the factors that may affect the generation of $\mathrm{PCDD} / \mathrm{Fs}$ during the cooking process. The raw materials were all cooked by a consistent procedure so the results in

Received: January 17, 2011

Revised: April 21, 2011

Accepted: April 25, 2011

Published: April 25, 2011 


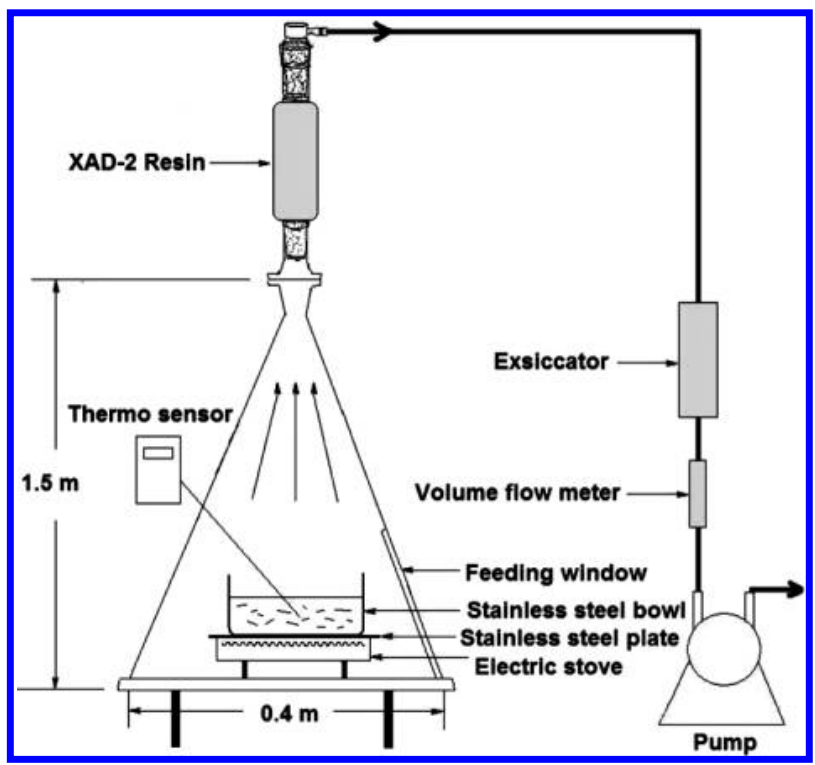

Figure 1. Stainless steel apparatus used for the cooking experiments.

Table 1. Raw Materials Used in Each Experiment

\begin{tabular}{|c|c|c|c|c|c|}
\hline & & \multicolumn{4}{|c|}{ raw materials } \\
\hline & & \multirow[b]{2}{*}{ beef/g } & \multirow{3}{*}{$\begin{array}{c}\text { soybean oil/g } \\
211.4\end{array}$} & \multicolumn{2}{|c|}{ additive } \\
\hline \multicolumn{2}{|c|}{ expt ID } & & & sucralose/g & $\mathrm{DCP} / \mathrm{g}$ \\
\hline \multirow[t]{3}{*}{ OC set } & $\mathrm{OC} 1$ & & & & \\
\hline & OC2 & & 203.2 & 44.4 & \\
\hline & OC3 & & 214.9 & & 40.2 \\
\hline \multirow[t]{2}{*}{ BC set } & $\mathrm{BC} 1$ & 601.3 & & & \\
\hline & $\mathrm{BC} 2$ & 604.2 & 200.9 & & \\
\hline \multirow[t]{4}{*}{ BS set } & BS1 & 606.5 & 201.9 & $4.2 \times 10^{-2}$ & \\
\hline & BS2 & 601.7 & 204.2 & 0.4 & \\
\hline & BS3 & 601.5 & 201.9 & 4.1 & \\
\hline & BS4 & 603.2 & 206.4 & 45.0 & \\
\hline \multirow[t]{5}{*}{ BD set } & BD1 & 599.4 & 202.2 & & $4.1 \times 10^{-5}$ \\
\hline & BD2 & 598.7 & 201.9 & & $4.0 \times 10^{-3}$ \\
\hline & BD3 & 602.1 & 199.2 & & 0.4 \\
\hline & BD4 & 599.8 & 200.6 & & 4.0 \\
\hline & BD5 & 612.3 & 208.5 & & 40.2 \\
\hline
\end{tabular}

the cooked samples could be compared. The raw materials used in each experiment (Table 1) were divided into four equal parts to ensure uniform heating during the cooking process in this study. Each of these four parts was placed in an individual stainless steel bowl (diameter = $13.5 \mathrm{~cm}$, height $=8 \mathrm{~cm}$ ), and these were heated sequentially. The samples were heated from room temperature on an electric stove set on high power for $15 \mathrm{~min}$. The gas phase for each of the four bowls was collected at a flow rate of $1.5 \mathrm{~m}^{3} \mathrm{~h}^{-1}$ both during cooking and for a further $10 \mathrm{~min}$ after cooking to trap the smoke produced during cooling (total time sampling time per experiment $=4 \times 25 \mathrm{~min}=100 \mathrm{~min}$ ). Afterward, the used XAD-2 resin was wrapped in aluminum foil to minimize sample contamination and loss. After all four parts of raw material in each experiment were processed by the same cooking procedure, the solid samples were combined and homogenized before storage. The residual liquor was mainly oil and a little water, and this was combined in a precleaned glass bottle. All of the samples collected were stored at $<-10{ }^{\circ} \mathrm{C}$ prior to analysis.

The temperatures of the plate and in the bowl during cooking were recorded by the thermo sensor. To aid understanding of the influence of cooking on the formation of PCDD/Fs, the heating time and temperature ranges used in this study were slightly wider than those found in everyday use.

Analytical Procedue. The entire analytical process was performed according to U.S. EPA Method 1613 for the determination of 17 toxic $\mathrm{PCDD} / \mathrm{F}$ congeners and tetra- through octa-chlorinated $\mathrm{PCDD} / \mathrm{F}$ homologue groups by isotope dilution high-resolution gas chromatography-high resolution mass spectrometry (HRGC-HRMS). ${ }^{13}$ Before extraction, the gas sample was spiked with ${ }^{13} \mathrm{C}_{12}$-labeled standards EN1948 ES (2,3,7,8-TCDD, 2,3,7,8-TCDF, 1,2,3,7,8-PeCDD, 2,3,4,7,8PeCDF, 1,2,3,4,7,8-HxCDD, 1,2,3,6,7,8-HxCDD, 1,2,3,4,7,8-HxCDF, 1,2,3,6,7,8-HxCDF, 2,3,4,6,7,8-HxCDF, 1,2,3,4,6,7,8-HpCDD, 1,2,3,4,6,7,8HpCDF, OCDD, OCDF). The solid sample and liquid sample were both spiked with ${ }^{13} \mathrm{C}_{12}$-labeled standards 1613 LCS (2,3,7,8-TCDD, 2,3,7,8-TCDF, 1,2,3,7,8-PeCDD, 2,3,4,7,8-PeCDF, 1,2,3,7,8-PeCDF, 1,2,3,4,7,8-HxCDD, 1,2,3,6,7,8-HxCDD, 1,2,3,4,7,8-HxCDF, 1,2,3,6,7,8HxCDF, 2,3,4,6,7,8-HxCDF, 1,2,3,7,8,9-HxCDF, 1,2,3,4,6,7,8-HpCDD, $1,2,3,4,6,7,8-\mathrm{HpCDF}, 1,2,3,4,7,8,9-\mathrm{HpCDF}, \mathrm{OCDD})$. The standards were added to control the sample treatment process. The gas sample and solid sample were then Soxhlet extracted with acetone and hexane $(1: 1, \mathrm{v} / \mathrm{v})$ for $24 \mathrm{~h}$.

After concentration, a cleanup procedure was applied to the gas and solid sample extracts and the liquid sample. First, a gel permeation chromatography (GPC) column packed with Biobeads SX-3 (Bio-Rad Laboratories, Inc., Hercules, CA) was used to remove high molecular weight interferences. Then adsorption chromatography was conducted using a column with $10 \mathrm{~g}$ of acidic silica gel $(22 \%, \mathrm{w} / \mathrm{w})$ and a multilayer silica gel column of (bottom to top) $1 \mathrm{~g}$ of silica gel, $2 \mathrm{~g}$ of $\mathrm{AgNO}_{3}$ silica gel $(10 \%, \mathrm{w} / \mathrm{w}), 1 \mathrm{~g}$ of silica gel, $4 \mathrm{~g}$ of basic silica gel $(33 \%, \mathrm{w} / \mathrm{w}), 1 \mathrm{~g}$ of silica gel, $8 \mathrm{~g}$ of acidic silica gel $(44 \%, \mathrm{w} / \mathrm{w})$, and $1-2 \mathrm{~cm}$ of anhydrous sodium sulfate. Finally, after purification by a basic alumina column, the PCDD/F fraction was obtained and then reduced to an appropriate volume. For recovery quantification, ${ }^{13} \mathrm{C}_{12}$-labeled standards 1613 ISS (1,2,3,4-TCDD, $1,2,3,7,8,9-\mathrm{HxCDD})$ were added immediately prior to injection.

HRGC-HRMS analysis of the PCDD/Fs was undertaken on an Agilent 6890 gas chromatograph coupled with an Autospec Ultima mass spectrometer (Waters Micromass, Manchester, U.K.) running with an EI source in SIM mode at resolution of $\geq 10000$. GC separation was performed on a DB-5MS fused silica capillary column $(60 \mathrm{~m} \times 250 \mu \mathrm{m}$ i.d. $\times 0.25 \mu \mathrm{m}$ film thickness) in splitless mode.

Quality Assurance and Control. Because of the complicated cooking and treatment process, duplicate samples were collected under only some conditions (experiments BC2, BS4, BD3, and BD5) (Table 1). No significant differences were found, and the relative percent difference (RPD) of the concentrations measured for duplicate experiments was $0.4-34 \%$.

To confirm the effects of the cooking process on PCDD/F production, the air was sampled between each experiment as a "field blank". The field blank samples were prepared and handled in the same manner as the gas samples, but no raw materials were added or heated. Laboratory blanks were incorporated routinely in the analysis of all gas samples $(n=18)$, solid samples ( $n=20 ; 2$ raw and 18 cooked), liquid samples $(n=7 ; 2$ raw and 5 cooked), and field blanks $(n=18)$.

In the laboratory blanks, the concentrations of the 7 PCDDs and 10 PCDFs with chlorines in the 2,3,7,8-positions were all below the limits of detection (LOD), which is equivalent to a signal-to-noise ratio of 3 . The detection limits varied for the different congeners and ranged from 0.004 to $0.08 \mathrm{pg} \mathrm{g}^{-1}$ (fresh weight). The field blanks gave higher results than 


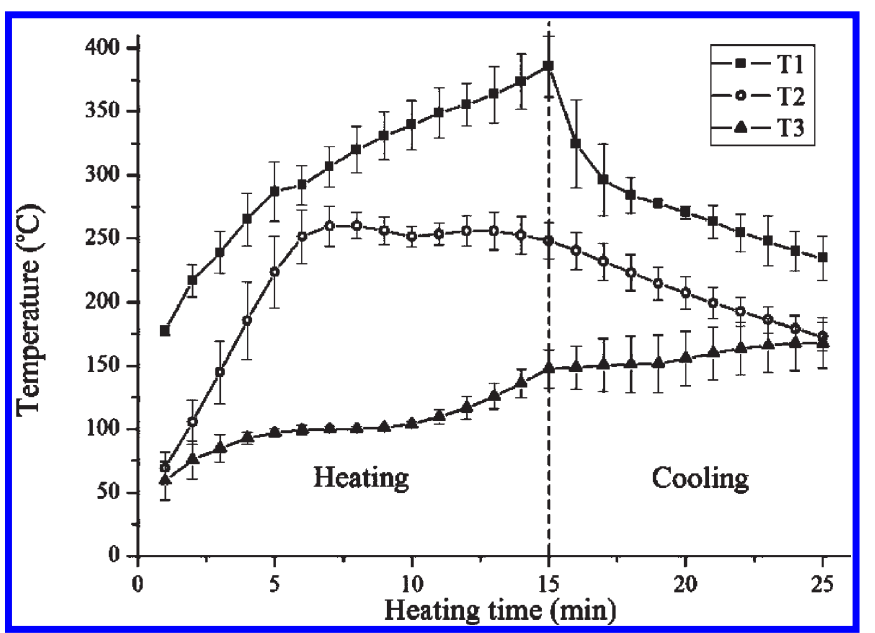

Figure 2. Variation of temperature during the cooking processes. T1, temperature of the plate (mean $\pm \mathrm{SD}$ ); $\mathrm{T} 2$, temperatures in the soybean oil in experiments $\mathrm{OC} 1-3$ (mean $\pm \mathrm{SD})$; T3, temperatures in the solid (beef) in experiments $\mathrm{BC} 1$ and $\mathrm{BC} 2, \mathrm{BS} 1-4$, and $\mathrm{BD} 1-5$ (mean $\pm \mathrm{SD})$.

the laboratory blanks, and 1,2,3,4,6,7,8-HpCDF, OCDF, 1,2,3,4,6,7,8$\mathrm{HpCDD}$, and OCDD were the most prevalent contaminants. The congeners that were detected had concentrations $2.5-12.8 \%$ those of the corresponding samples. Because of the fluctuation of these relatively low blank levels, all of the sample results were not blank corrected in this study.

The recoveries for gas, solid, and liquid samples varied between 39 and $115 \%$ and met the limits of European Method EN $1948^{14}$ and U.S. EPA Method $1613 .^{13}$

\section{RESULTS AND DISCUSSION}

The concentrations of PCDD/Fs were determined in raw soybean oil and five selected residual liquor samples (experiments $\mathrm{OC} 2, \mathrm{OC} 3, \mathrm{BC} 2, \mathrm{BS} 4$, and BD5). The results in these liquid phase samples were all rather low, and most of the target PCDD/F congeners were not detected. Due to the analytical system error, the results of the liquid phase were ignored to avoid high error in the data.

Influence of Cooking on Soybean Oil and Organic Chlorides. To simplify the influencing factors during cooking, soybean oil was the only carbon source in the OC set of experiments (Table 1). The soybean oil was heated on its own (experiment OC1) and then separately with the organic chloride additives sucralose (experiment OC2) and 1,3-DCP (experiment OC3). The temperature in the oil was maintained at around $250^{\circ} \mathrm{C}$ for about $10 \mathrm{~min}$ (Figure 2).

Few $\mathrm{PCDD} / \mathrm{F}$ congeners were detected in the gas phase of OC1 (OC1-G). By contrast, many PCDD/Fs were generated in the gas phase (OC2-G, OC3-G) when the chlorine-containing additives were included in experiments OC2 and OC3. In consideration of the raw materials and temperatures during the OC set of cooking experiments, it is obvious that PCDD/F formation is affected by the presence of the organic chlorinecontaining additive. As reported, the smoke (gas phase) obtained from heating soybean oil contains hydrocarbons, such as polycyclic aromatic hydrocarbons, ${ }^{15}$ which are potential carbon sources for the formation of PCDD/Fs. ${ }^{16}$ When organic chlorine-containing additives were present in the raw materials (experiments OC2 and OC 3 ), chlorine free radicals could be produced during the cooking process at high temperature. Because of this, PCDD/Fs are likely to be generated in the gas

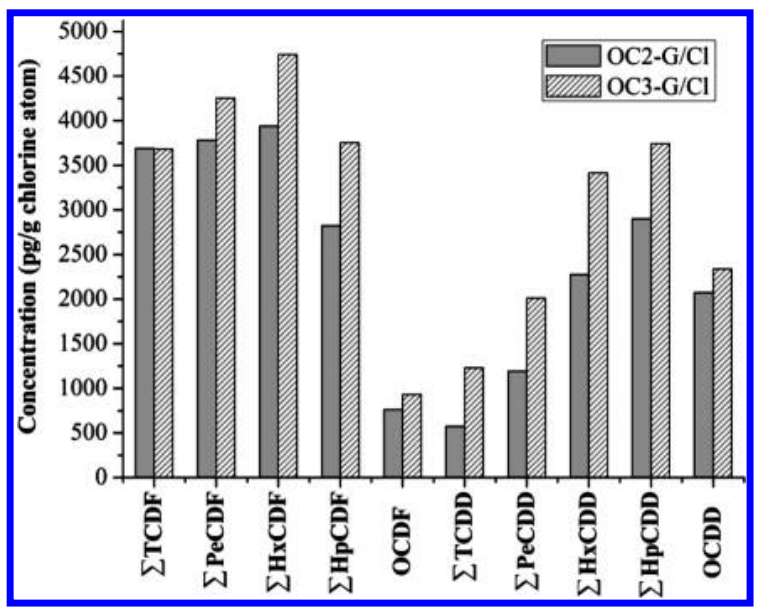

Figure 3. Concentrations of tetra- through octachlorinated PCDD/F homologue groups generated in the gas phases of cooking experiments OC2 and OC3. Concentrations were calculated on the basis of the chlorine atom weight contained in the chlorinated additives included in OC2 and OC3.

phase or on the surface of the oil during cooking under appropriate conditions. These results suggest that when cooking at high temperatures, such as frying, more attention should be given to use of organic chlorides. To avoid unintentional generation of $\mathrm{PCDD} / \mathrm{Fs}$, it is better not to use flavorings that contain organic chlorine or to use alternatives.

Figure 3 presents the concentrations of tetra- through octachlorinated PCDD/F homologue groups generated in the gas phases of experiments OC2 and OC 3 . No significant differences were found between the quantity of PCDD/Fs formed in OC2 (sucralose additive) and in OC3 (1,3-DCP additive). The two homologue concentration profiles were similar, and higher levels of PCDFs compared to PCDDs were both found in the gas phase. This suggests that PCDD/Fs are produced through similar pathways in OC2 and OC3. It is generally considered that de novo pathways lead preferentially to the formation of PCDFs. ${ }^{16}$ Besides, it has been reported that the oxidation of polychlorobenzenes would produce more PCDFs than PCDDs. ${ }^{17}$ Because of the limited data and complex reaction mechanisms, further investigation is needed to better understand the PCDD/F formation pathways of cooking oil and organic chlorides.

Influence of Cooking on Beef, Soybean Oil, and Organic Chlorides. To simulate the real cooking process, beef was added to the raw materials, and the cooking process conducted was similar to frying. Because of evaporation of water and release of fat, the cooked solid samples decreased in weight by $57-74 \%$ ( mean $=64 \%$ ). To correct for this weight loss, the concentrations in the cooked solid samples and gas samples collected during cooking were recalculated on the basis of the weight of the original fresh beef.

To examine the factors affecting the formation of PCDD/Fs, beef was cooked with different materials in a series of experiments (Table 1). The temperature in the beef in these experiments was below $200{ }^{\circ} \mathrm{C}$ throughout the cooking process (Figure 2), which is much lower than the temperature in the OC set of experiments. Compared to the results in the gas phase from experiments OC2 and OC3, the quantities of PCDD/Fs detected in the gas phase from experiments BS4 and BD5 were much lower. Because the same mass of organic chloride was added to each of these experiments, the key reason for this 
Table 2. Concentrations (Picograms per Gram) of Tetra- through Octachlorinated PCDD/F Homologue Groups in Raw Beef and Cooked Samples (Solid and Gas Samples) for the BC, BS, and BD Sets of Experiments ${ }^{a}$

\begin{tabular}{|c|c|c|c|c|c|c|c|c|c|c|c|c|c|}
\hline $\begin{array}{c}\text { sample } \\
\text { ID }\end{array}$ & $\Sigma \mathrm{TCDF}$ & $\Sigma \mathrm{PeCDF}$ & $\Sigma \mathrm{HxCDF}$ & $\Sigma \mathrm{HpCDF}$ & OCDF & $\Sigma T C D D$ & $\Sigma \mathrm{PeCDD}$ & $\Sigma \mathrm{HxCDD}$ & $\Sigma \mathrm{HpCDD}$ & OCDD & $\begin{array}{c}\Sigma \mathrm{PCDF} \\
\text { (tetra to octa) }\end{array}$ & $\begin{array}{c}\Sigma \mathrm{PCDD} \\
\text { (tetra to octa) }\end{array}$ & $\begin{array}{c}\Sigma \mathrm{PCDD} / \\
\Sigma \mathrm{PCDF}\end{array}$ \\
\hline beef (raw) & 0.15 & 0.38 & 0.34 & 0.19 & 0.26 & 0.018 & 0.054 & 0.11 & 0.15 & 0.34 & 1.32 & 0.67 & 0.5 \\
\hline BC1-gas & 1.33 & 1.30 & 1.06 & 0.46 & 0.10 & 0.32 & 0.55 & 0.46 & 0.38 & 0.20 & 4.26 & 1.92 & 0.4 \\
\hline BC1-solid & 0.17 & 0.64 & 0.52 & 0.40 & 0.57 & 0.01 & 0.01 & 0.11 & 0.79 & 3.38 & 2.30 & 4.30 & 1.9 \\
\hline BC2-gas ${ }^{b}$ & 1.85 & 1.49 & 0.46 & 0.24 & 0.10 & 0.44 & 0.44 & 0.38 & 0.16 & 0.21 & 4.15 & 1.63 & 0.4 \\
\hline BC2-solid ${ }^{b}$ & 0.74 & 0.37 & 0.25 & 0.39 & 1.53 & 0.18 & 0.13 & 0.14 & 0.96 & 4.49 & 3.28 & 5.89 & 1.8 \\
\hline BS1-gas & 8.80 & 8.00 & 4.42 & 1.48 & 0.16 & 1.18 & 1.66 & 1.46 & 1.20 & 0.63 & 22.9 & 6.12 & 0.3 \\
\hline BS1-solid & 3.61 & 3.52 & 5.32 & 4.73 & 0.85 & 0.53 & 0.64 & 1.19 & 5.98 & 4.74 & 18.0 & 13.1 & 0.7 \\
\hline BS2-gas & 11.3 & 9.70 & 5.07 & 1.40 & 0.15 & 1.79 & 1.64 & 1.00 & 1.02 & 0.66 & 27.7 & 6.11 & 0.2 \\
\hline BS2-solid & 1.95 & 1.15 & 2.68 & 2.76 & 0.49 & 0.22 & 0.17 & 0.62 & 3.43 & 3.02 & 9.04 & 7.47 & 0.8 \\
\hline BS3-gas & 26.7 & 21.2 & 9.38 & 2.45 & 0.27 & 3.20 & 3.91 & 2.61 & 1.63 & 0.80 & 59.9 & 12.2 & 0.2 \\
\hline BS3-solid & 1.32 & 1.54 & 6.57 & 6.65 & 0.83 & 0.16 & 0.28 & 1.44 & 5.47 & 4.71 & 16.9 & 12.1 & 0.7 \\
\hline BS4-gas ${ }^{b}$ & 15.2 & 13.6 & 12.0 & 5.14 & 0.60 & 2.03 & 3.75 & 5.13 & 3.19 & 1.23 & 46.6 & 15.3 & 0.3 \\
\hline BS4-solid ${ }^{b}$ & 2.97 & 2.93 & 6.51 & 5.85 & 0.88 & 0.22 & 0.41 & 1.33 & 6.25 & 4.84 & 19.1 & 13.1 & 0.7 \\
\hline BD1-gas & 11.8 & 10.8 & 5.27 & 1.45 & 0.16 & 1.46 & 1.80 & 1.05 & 0.95 & 0.68 & 29.4 & 5.95 & 0.2 \\
\hline BD1-solid & 1.95 & 1.80 & 4.10 & 2.74 & 0.57 & 0.19 & 0.15 & 0.43 & 4.57 & 4.88 & 11.2 & 10.2 & 0.9 \\
\hline BD2-gas & 9.81 & 7.53 & 5.04 & 1.68 & 0.17 & 1.25 & 1.51 & 1.11 & 0.95 & 0.62 & 24.2 & 5.44 & 0.2 \\
\hline BD2-solid & 1.00 & 1.16 & 3.23 & 2.63 & 0.54 & 0.08 & 0.07 & 0.56 & 4.50 & 4.44 & 8.57 & 9.65 & 1.1 \\
\hline BD3-gas ${ }^{b}$ & 7.94 & 5.17 & 2.85 & 0.93 & 0.10 & 0.89 & 0.75 & 0.61 & 0.69 & 0.55 & 17.0 & 3.48 & 0.2 \\
\hline BD3-solid $^{b}$ & 0.67 & 0.81 & 2.72 & 2.16 & 0.46 & 0.06 & 0.06 & 0.44 & 3.83 & 3.64 & 6.81 & 8.02 & 1.2 \\
\hline BD4-gas & 24.7 & 22.6 & 11.4 & 2.89 & 0.32 & 3.24 & 4.10 & 2.40 & 1.61 & 0.77 & 61.9 & 12.1 & 0.2 \\
\hline BD4-solid & 3.32 & 2.69 & 4.43 & 3.76 & 0.70 & 0.37 & 0.37 & 0.74 & 2.63 & 4.37 & 14.9 & 8.47 & 0.6 \\
\hline BD5-gas ${ }^{b}$ & 122 & 111 & 86.4 & 39.6 & 6.07 & 32.5 & 54.3 & 51.9 & 28.1 & 12.1 & 365 & 179 & 0.5 \\
\hline BD5-solid $^{b}$ & 4.04 & 3.89 & 3.53 & 2.34 & 1.08 & 1.77 & 2.08 & 2.47 & 3.12 & 3.85 & 14.9 & 13.3 & 0.9 \\
\hline
\end{tabular}

${ }^{a}$ Concentrations in cooked gas and solid samples were calculated on the basis of the original fresh beef weight. ${ }^{b}$ Average concentrations of duplicate samples.

difference might be the decrease in the cooking temperature when beef was added in experiments BS4 and BD5.

The concentrations of tetra- through octachlorinated PCDD $/ \mathrm{F}$ homologue groups in raw beef and cooked samples (solid and gas samples) for the BC, BS, and BD sets of experiments are shown in Table 2, and Figure 4 presents the concentrations of PCDD/F toxic equivalents (TEQ). The toxic equivalency factors (TEFs) for the TEQ calculation are established by the World Health Organization (WHO) ${ }^{18}$ TEQs were calculated with half of the LOD for congener concentrations that were below the $\operatorname{LOD}(\mathrm{S} / \mathrm{N}=3)$. The average $\mathrm{PCDD} / \mathrm{F}$ concentration of raw beef in this study was $0.069 \mathrm{pg}$ of $\mathrm{TEQ}^{-1}$ (fresh weight), which is similar to the level for meat reported in a national survey of foods of animal origin in China $\left(0.06-0.21\right.$ pg of TEQ $\left.g^{-1}\right) .{ }^{19}$ This means the beef used in this study is representative of that consumed in China.

The BC set of experiments was performed without chlorinated additives, and different $\mathrm{PCDD} / \mathrm{F}$ concentrations were found in the solid phase (BC1-S, BC2-S) and the gas phase (BC1-G, BC2-G) samples. Most of the 17 toxic PCDD/F congeners were not detected in the solid phase samples. By contrast, all of the target congeners were detected quantitatively in the corresponding gas samples, and the two gas phase samples had similar congener concentration profiles (Figure 5). Compared with the PCDD/F concentrations in raw beef, no obvious changes were observed in the sum concentrations of the gas and solid phases of the cooked

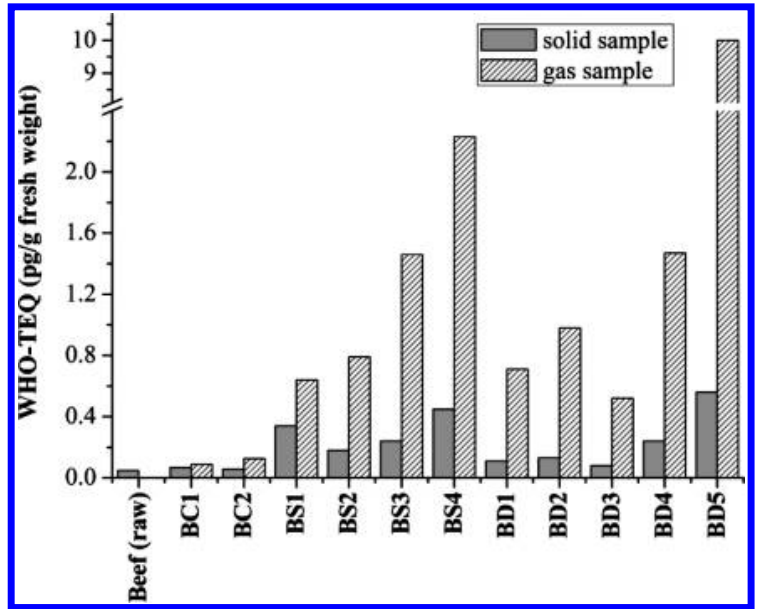

Figure 4. Concentrations of $\mathrm{PCDD} / \mathrm{F}$ toxic equivalents (TEQ) in raw beef and cooked samples (solid and gas samples) for the BC, BS, and BD sets of experiments.

samples from the BC set of experiments (Table 2) when the sampling limitations and analytical imprecision were taken into consideration. It has been reported that changes in the concentrations of $\mathrm{PCDD} / \mathrm{Fs}$ between raw and cooked products can be 


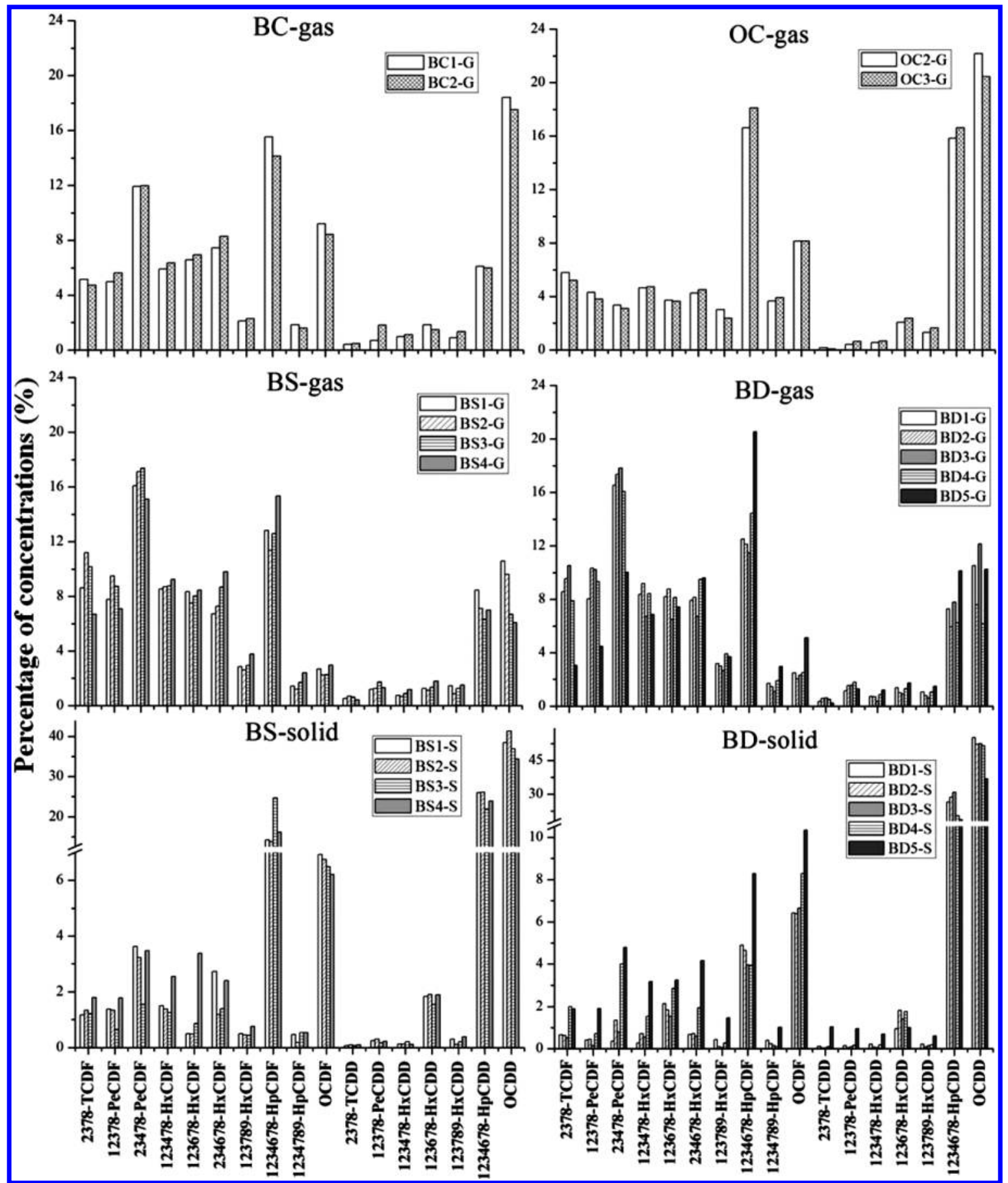

Figure 5. Concentration profiles of 17 toxic PCDD/F congeners in gas and solid samples.

explained by loss of water and elimination of PCDD/Fs with released fat. ${ }^{7}$ Thus, $\mathrm{PCDD} / \mathrm{Fs}$ detected in the gas phase of experiments $\mathrm{BC} 1$ and $\mathrm{BC} 2$ may have transferred from the raw materials (solid phase).

To verify the influence of organic chlorides on PCDD/F formation during cooking, various quantities of sucralose (BS set experiments) and 1,3-DCP (BD set experiments) were added separately to the raw materials. The PCDD/F concentrations in products cooked with the chlorinated additives were higher than those cooked without them, and the TEQ concentrations of $\mathrm{PCDD} / \mathrm{Fs}$ increased as the mass of organic chloride additive increased (Figure 4).
As shown in Figure 5, the congener concentration profiles of the BS set of experiments were similar to those of the BD set of experiments in both the solid and gas phases. However, the profiles in the gas phases of the $\mathrm{BS}$ and $\mathrm{BD}$ sets of experiments were different from those of the OC set of experiments. This means that the PCDD/Fs detected in the gas phases of the BS and $\mathrm{BD}$ sets of experiments may be generated by the cooking process and transferred from the raw materials.

The addition of organic chlorides affected the change of $\mathrm{PCDD} / \mathrm{F}$ concentrations in the gas and solid phase samples and their congener concentration profiles differently. The change in the PCDD/F concentrations with the change in quantity of the 
chlorinated additive was greater in the gas phase than in the solid phase (Table 2). This was particularly apparent in experiment $\mathrm{BD} 5$, where the formation of PCDD/Fs was enhanced more in the gas phase than in the solid phase with the addition of abundant 1,3-DCP (Figure 4). The concentrations of lower chlorinated $\mathrm{PCDD} / \mathrm{F}$ congeners in the gas phase were higher than those in the solid phase (Figure 5). The differences in the $\mathrm{PCDD} / \mathrm{F}$ levels in the gas and solid phase samples may be explained as follows. First, in these cooking experiments PCDD/ Fs are more likely to form in the gas phase than in the solid phase. Second, PCDD/Fs may be transferred from the solid phase to the gas phase at high temperature. Because the lower chlorinated $\mathrm{PCDD} / \mathrm{F}$ homologues have relatively high vapor pressure compared to the higher chlorinated homologues, the lower chlorinated congeners can be transferred more readily to the gas phase. Thus, it was found that PCDD/Fs were more likely to be present in the gas phase than the solid phase. These results suggest that good ventilation should be maintained during cooking to decrease human intake of $\mathrm{PCDD} / \mathrm{Fs}$ through air and reduce exposure risk to PCDD/Fs.

\section{AUTHOR INFORMATION}

\section{Corresponding Author}

*E-mail: zhengmh@rcees.ac.cn. Phone: +86 10 62849172. Fax: +861062849172.

\section{Funding Sources}

This study was supported by the National Natural Science Foundation of China (20777086 and 20921063).

\section{REFERENCES}

(1) McKay, G. Dioxin characterisation, formation and minimisation during municipal solid waste (MSW) incineration: review. Chem. Eng. J. 2002, 86, 343-368.

(2) Altarawneh, M.; Dlugogorski, B. Z.; Kennedy, E. M.; Mackie, J. C. Mechanisms for formation, chlorination, dechlorination and destruction of polychlorinated dibenzo-p-dioxins and dibenzofurans (PCDD/Fs). Proo. Enerov Combust. Sci. 2009, 35, 245-274.

(3) Travis, C. C.; Hattemerfrey, H. A. Human exposure to dioxin. Sci. Total Environ. 1991, 104, 97-127.

(4) Fuerst, P.; Beck, H.; Theelen, R. Assessment of human intake of PCDDs and PCDFs from different environmental sources. Toxic Substances 1992, 12, 133-150.

(5) Baars, A. J.; Bakker, M. I.; Baumann, R. A.; Boon, P. E.; Freijer, J. I.; Hoogenboom, L. A. P.; Hoogerbrugge, R.; van Klaveren, J. D.; Liem, A. K. D.; Traag, W. A.; de Vries, J. Dioxins, dioxin-like PCBs and nondioxin-like PCBs in foodstuffs: occurrence and dietary intake in The Netherlands. Toxicol. Lett. 2004, 151, 51-61.

(6) Schecter, A.; Dellarco, M.; Päpke, O.; Olson, J. A comparison of dioxins, dibenzofurans and coplanar PCBs in uncooked and broiled ground beef, catfish and bacon. Chemosphere 1998, 37, 1723-1730.

(7) Rose, M.; Thorpe, S.; Kelly, M.; Harrison, N.; Startin, J. Changes in concentration of five $\mathrm{PCDD} / \mathrm{F}$ congeners after cooking beef from treated cattle. Chemosphere 2001, 43, 861-868.

(8) Tsutsumi, T.; Iida, T.; Hori, T.; Nakagawa, R.; Tobiishi, K.; Yanagi, T.; Kono, Y.; Uchibe, H.; Matsuda, R.; Sasaki, K.; Toyoda, M. Recent survey and effects of cooking processes on levels of PCDDs, PCDFs and Co-PCBs in leafy vegetables in Japan. Chemosphere 2002, 46, 1443-1449.

(9) Hori, T.; Nakagawa, R.; Tobiishi, K.; Iida, T.; Tsutsumi, T.; Sasaki, K.; Toyoda, M. Effects of cooking on concentrations of polychlorinated dibenzo- $p$-dioxins and related compounds in fish and meat. I. Agric. Food Chem. 2005, 53, 8820-8828.
(10) Perello, G.; Marti-Cid, R.; Castell, V.; Llobet, J. M.; Domingo, $\mathrm{J}$. L. Influence of various cooking processes on the concentrations of PCDD/PCDFs, PCBs and PCDEs in foods. Food Control 2010, 21, $178-185$.

(11) Petroske, E.; Zaylskie, R. G.; Feil, V. J. Reduction in polychlorinated dibenzodioxin and dibenzofuran residues in hamburger meat during cooking. I. Agric. Food Chem. 1998, 46, 3280-3284.

(12) Crews, C.; Hasnip, S.; Chapman, S.; Hough, P.; Potter, N.; Todd, J.; Brereton, P.; Matthews, W. Survey of chloropropanols in soy sauces and related products purchased in the UK in 2000 and 2002. Food Addit. Contam. 2003, 20, 916-922.

(13) U.S. Environmental Protection Agency, 1997. Method 1613, Tetra- through octa-chlorinated dioxins and furans by isotope dilution HRGC/HRMS.

(14) European Committee for Standardization. 1997. BS EN 1948$1 / 2 / 3$ Stationary source emissions - determination of the mass concentration of PCDDs/PCDFs.

(15) Chen, B. H.; Chen, Y. C. Formation of polycyclic aromatic hydrocarbons in the smoke from heated model lipids and food lipids. L. Agric. Food Chem. 2001, 49, 5238-5243.

(16) Tuppurainen, K.; Asikainen, A.; Ruokojärvi, P.; Ruuskanen, J. Perspectives on the formation of polychlorinated dibenzo-p-dioxins and dibenzofurans during municipal solid waste (MSW) incineration and other combustion processes. Acc. Chem. Res. 2003, 36, 652-658.

(17) Sommeling, P. M.; Mulder, P.; Louw, R. Formation of PCDFs during chlorination and oxidation of chlorobenzene in chlorine/oxygen mixtures around $340^{\circ} \mathrm{C}$. Chemosphere 1994, 29, 2015-2018.

(18) Van den Berg, M.; Birnbaum, L. S.; Denison, M.; De Vito, M.; Farland, W.; Feeley, M.; Fiedler, H.; Hakansson, H.; Hanberg, A.; Haws, L.; Rose, M.; Safe, S.; Schrenk, D.; Tohyama, C.; Tritscher, A.; Tuomisto, J.; Tysklind, M.; Walker, N.; Peterson, R. E. The 2005 World Health Organization reevaluation of human and mammalian toxic equivalency factors for dioxins and dioxin-like compounds. Toxicol. Sci. 2006, 93, 223-241.

(19) Li, J. G.; Wu, Y. N.; Zhang, L.; Zhao, Y. F. Dietary intake of polychlorinated dioxins, furans and dioxin-like polychlorinated biphenyls from foods of animal origin in China. Food Addit. Contam. A 2007, 24, 186-193. 